\title{
In vitro ANTI-INFLAMMATORY AND ANTIOXIDANT EVALUATION OF AN INDIGENOUS MEDICINAL PLANT - Pterospermum rubiginosum
}

\section{Rajamohanan J Anish, Arun A Rauf*}

Department of Biochemistry, University of Kerala, Trivandrum, India

Received - July 30, 2021; Revision - October 17, 2021; Accepted - October 25, 2021

Available Online - October 30, 2021

DOI: http://dx.doi.org/10.18006/2021.9(5).687.696

KEYWORDS
Anti-inflammatory
Antioxidants
Bark extracts
Free radicals
Raw 264.7 cells

\begin{abstract}
The current study was carried out to determine the antioxidant potential, anti-inflammatory activity, and cellular viability of Pterospermum rubiginosum (PR), a tropical tree endemic to the Western Ghats. The antioxidant activities of the PR bark methanolic (PRME) and aqueous extract (PRAQ) were tested using ABTS as well as superoxide, nitric oxide, and hydroxyl radical assays. Total antioxidant activity was evaluated by adopting the colorimetric method and correlation with their antioxidant activities was derived by Pearson co-efficient analysis. The PRME showed the highest ABTS radical scavenging activity, $\mathrm{EC}_{50}(46.09 \mu \mathrm{g} / \mathrm{ml})$ followed by PRAQ $(52.08 \mu \mathrm{g} / \mathrm{ml})$. Furthermore, the PRME exhibited the highest scavenging activity against superoxide, nitric oxide, and hydroxyl radicals. The MTT assay results revealed good cellular viability up to a concentration of $100 \mu \mathrm{g} / \mathrm{ml}$ with an $\mathrm{EC}_{50}(106.869 \mu \mathrm{g} / \mathrm{ml})$. The inflammatory mediators such as Cox-2, IL-1 $\beta$, IL-6, and NF-kB were reduced during the treatment of PRME in LPS stimulated RAW cells. The stress marker in rat liver cells such as glutathione reductase (GR), glutathione peroxidase (GPx), and reduced glutathione (GSH) levels was found in normal levels when compared to the untreated group of rats. The antioxidant enzyme superoxide dismutase and catalase also exhibited notable bioactivity in PRME treated groups up to a concentration of $1000 \mu \mathrm{g} / \mathrm{ml}$. The present study showed excellent In vitro and In vivo antioxidant activity; the potent antiinflammatory ability of PRME in reducing the LPS induced inflammation in cell culture conditions.
\end{abstract}

* Corresponding author

E-mail: arunarauf@keralauniversity.ac.in (Arun A Rauf)

Peer review under responsibility of Journal of Experimental Biology and Agricultural Sciences.

Production and Hosting by Horizon Publisher India [HPI] (http://www.horizonpublisherindia.in/).

All rights reserved.
All the articles published by Journal of Experimental Biology and Agricultural Sciences are licensed under a Creative Commons Attribution-NonCommercial 4.0 International License Based on a work at www.jebas.org.

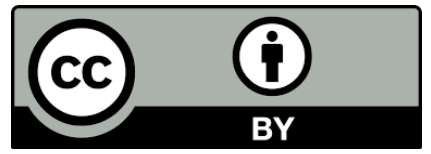




\section{Introduction}

Reactive oxygen species (ROS) is a biologically harmful group of free radicals formed in our body during cellular metabolism, under the influence of various secondary metabolites and coenzymes (Pizzino et al., 2017). Any change in metabolic equilibrium will lead to the excess production of free radicals, including ROS, which is a sensitive trigger for oxidative stress mechanism. Various food materials are a rich source of natural antioxidants and are found to be very effective for scavenging unwanted radicals, thereby minimizing the complications related to degenerative diseases and aging (Shields et al., 2021). The oxidation induced by ROS such as nitric oxide radical, superoxide radical, hydroxyl radical, hydrogen peroxide $\left(\mathrm{H}_{2} \mathrm{O}_{2}\right)$, and singlet oxygen $\left(\mathrm{O}_{2}\right)$, resulting in cell membrane disintegration, protein damage, and mutation, which may further lead to diseases such as diabetes, cancer, liver injury and cardiovascular disease (Srivastava et al., 2017). During mitochondrial respiratory chain reaction, superoxide anion is produced as natural by-products of cellular metabolism. The main sources of extracellular ROS are UV and other ionizing radiation and pollutants (Pizzino et al., 2017).

Oxidative stress occurs when the critical balance between ROS production and the endogenous antioxidant defense gets altered due to severe oxidative damage. For maintaining the oxidant status and to repair the redox equilibrium, cells undergo a self-adjustment to homeostatic changes; otherwise, we have to supplement antioxidants (Kurutas, 2015). Antioxidants have a synthetic or natural origin that reacts with free radicals and reduces their lethal effects in our body by neutralizing them. The imbalance between oxidants and antioxidants in the body leads to the damage of macromolecules such as enzymes and proteins in various regulatory and metabolic pathways and diverse health problems including lifestyle disorders. Therefore, homeostasis between antioxidants and oxidants is considered to be a crucial mechanism that reduces ROS and helps to maintain a healthy biological status (Hasanuzzaman et al., 2020).

Due to the limited availability of natural antioxidants, several synthetic molecules have been used as an alternative in the pharmaceutical industry, but long-term use of these chemicals can result in severe side effects including DNA damage, induce premature senescence, and other related complications (Kornienko et al., 2019). Due to ease of availability, synthetic antioxidants such as butylated hydroxyanisole (BHA) and butylated hydroxytoluene (BHT) are commonly used in food preservation and recent animal toxicity (In vivo) studies have validated that, these compounds are highly lethal and can induce apoptosis and promote tumor growth (Xu et al., 2021). Strict implementation of dietary restrictions is necessary to minimize systemic disorders, by European Food Safety Authority (EFSA) \& Food and Drug Administration (FDA) (Lourenço et al., 2019). So finding novel safe antioxidants from natural sources, especially plant derivatives, is of great interest in food and pharmaceutical applications. Plant extracts have been widely used as effective remedies for the prevention and treatment of multiple health issues for centuries by almost every known culture. The traditional medicinal system of India, Ayurveda has been practiced for more than 5,000 years and decoctions and extracts from medicinal plants remain an essential component of its practice (Subhose et al., 2005; Babich et al.. 2020). There is a diverse variety of secondary metabolites isolated from different medicinal plants exhibiting excellent antiinflammatory, anticancer, analgesic, antibacterial, antiviral activities and it is mainly due to the presence of novel antioxidants (Tungmunnithum et al., 2018).

Pterospermum rubiginosum (Sterculiaceae), "Ellooti" bark, or "Ellooripatta" is a tropical tree endemic to the Western Ghats, Kerala, and has been previously identified by Kanikaran tribes to exert beneficial effects on bone fractures preventing bone loss and promoting bone health (Anish et al., 2021; Vijayan et al., 2007). There is still a lack of knowledge regarding the exact mechanism behind the bioactivity of $P$. rubiginosum and it requires further study for potential therapeutic applications. Other than traditional knowledge, there have been no detailed reports on the antioxidant activities of this plant; hence the present work investigates the complete antioxidant free radical scavenging profile of methanolic and aqueous fractions from $P$. rubiginosum bark. Best of our knowledge, there has been no previous literature being available on the anti-inflammatory and animal experimental studies of $P$. rubiginosum methanolic bark extract.

\section{Materials and Methods}

\subsection{Plant Materials and reagents}

The bark of $P$. rubiginosum was collected from the Kottur forest range, Thiruvananthapuram district of Kerala with the help of tribals. The plant voucher specimen is kept in the herbarium of the Department of Botany, University of Kerala, India with a voucher number of KUBH 6189. All the reagents, methanol, and organic solvents (Merck Millipore, Germany) were analytical grade. The experiment was conducted using cell culture media, antibiotics (Sigma Aldrich, USA) \& inflammatory markers (Santa Cruz, USA).

\subsection{Sample extraction}

After removing exfoliated outer bark, the inner bark of $P$. rubiginosum was shade dried for 3-4 weeks. The dried bark was powdered, and $500 \mathrm{~g}$ of the powdered material was extracted with methanol in a soxhlet apparatus for $72 \mathrm{hrs}$. The extract was then concentrated with the help of a rotary evaporator and qualitative analysis of their active ingredients was carried out using standard 
procedures (Azmin \& Nor, 2020). For water extraction, $100 \mathrm{~g}$ powdered bark was mixed with $1 \mathrm{~L}$ distilled water and extracted with the help of a magnetic stirrer.

\subsection{Total Antioxidant Activity}

The total antioxidant activity (TAA) of both methanolic and aqueous extracts of $P$. rubiginosum was determined by adapting the method used by Subhasree et al. (2009) with slight modifications. Different concentrations of both the extracts (12.5$500 \mu \mathrm{g} / \mathrm{ml}$ ) from a stock concentration of $1 \mathrm{mg} / \mathrm{ml}$ were mixed with $3 \mathrm{ml}$ of reagent solution $\left(0.6 \mathrm{M} \mathrm{H}_{2} \mathrm{SO}_{4}, 28 \mathrm{mM}\right.$ sodium phosphate, and $4 \mathrm{mM}$ ammonium molybdate) in capped test tubes. The tube containing the reaction solutions was incubated in a boiling water bath at $95^{\circ} \mathrm{C}$ for 90 minutes. After cooling to room temperature, the absorbance of the solution was measured at $695 \mathrm{~nm}$ against a blank ( $0.3 \mathrm{ml}$ of methanol was used in place of PRME). TAA was determined based on the number of gram equivalents of ascorbic acid.

$$
\% \text { Inhibition }=\frac{(\text { Control }- \text { Test })}{\text { Control }} \times 100
$$

\subsection{ABTS Assay}

The radical mono-cation of 2, 2'azinobis 3 ethyl benzothiazoline 6sulfonic acid (ABTS) was generated by oxidation of ABTS with potassium persulfate (a blue chromogen) and is reduced in the presence of hydrogen donating antioxidants, following the method of Re et al (1999). ABTS (20 mM) and potassium persulfate (17 $\mathrm{mM}$ ) were prepared as the stock solution and kept overnight at room temperature in the dark. The stock solution was diluted by mixing $1 \mathrm{~mL}$ of ABTS solution with $60 \%$ methanol to obtain an absorbance of $0.708 \pm 0.001$ units at $734 \mathrm{~nm}$. $1 \mathrm{ml}$ of distilled water was added to $0.2 \mathrm{ml}$ of 5 different concentrations of the sample (5$250 \mu \mathrm{g} / \mathrm{ml}$ from a stock concentration of $2 \mathrm{mg} / \mathrm{ml}$ ) and $0.16 \mathrm{ml}$ of ABTS solution was added and made up to the final volume of 1.36 $\mathrm{ml}$. A tube with an equivalent amount of distilled water but without the test sample served as a control. The decrease in absorbance was taken after $20 \mathrm{~min}$ at $734 \mathrm{~nm}$; against ascorbic acid as standard. The following formula was used to calculate the percentage inhibition:

$$
\% \text { Inhibition }=\frac{(\text { Control }- \text { Test })}{\text { Control }} \times 100
$$

\subsection{Nitric Oxide Scavenging Activity}

In aqueous solutions at physiological $\mathrm{pH}$, sodium nitroprusside spontaneously produces nitric oxide, which interacts with oxygen to create nitrite ions, which can then be measured with the Griess reagent (Patel et al., 2010). A solution of sodium nitroprusside $\left(5 \mathrm{mmolL}^{-1}\right)$ was mixed with different concentrations of extracts $(5$ $250 \mu \mathrm{g} / \mathrm{ml}$ ) from a stock concentration of $2 \mathrm{mg} / \mathrm{ml}$ and incubated at $25^{\circ} \mathrm{C}$ for 30 minutes. A control without test compound, but an equivalent amount of distilled water was taken. The incubated solution (after 30 minutes) was diluted with Griess reagent (1\% sulphanilamide, $2 \%$ phosphoric acid, and $0.1 \%$ N-1-naphthyl ethylene diamine dihydrochloride). The chromophore generated in this study was measured at $546 \mathrm{~nm}$ and with reference standards of gallic acid was quantified in terms of its scavenging activity.

$$
\% \text { Inhibition }=\frac{(\text { Control }- \text { Test })}{\text { Control }} \times 100
$$

\subsection{Super Oxide Scavenging Assay}

NADH oxidation generates a superoxide anion in the riboflavinNADH system, which is detected by reducing NBT to blue formazan products (Valento et al., 2002). From the stock solution of $2 \mathrm{mg} / \mathrm{ml}, 5$ different concentrations of the sample $(5-250 \mu \mathrm{g} / \mathrm{ml})$ mixed with $0.05 \mathrm{ml}$ of riboflavin $(0.12 \mathrm{mM}), 0.2 \mathrm{ml}$ of EDTA solution $(0.1 \mathrm{mM})$, and $0.1 \mathrm{ml}$ of NBT solution $(1.5 \mathrm{mM})$ were taken in test tubes, reaction mixtures were mixed with phosphate buffer $(0.067 \mathrm{M})$, a control without test compound, but distilled water in an equivalent amount. Triggering of reaction was done by illuminating the above solutions for 5 mins using a fluorescent lamp. After 30 minutes, the absorbance was measured at $560 \mathrm{~nm}$ using a UV-visible spectrophotometer, percentage of scavenging superoxide anion generation was calculated as

$$
\% \text { Inhibition }=\frac{(\text { Control }- \text { Test })}{\text { Control }} \times 100
$$

\subsection{Hydroxyl Radical Scavenging Activity}

The assay was based on a method to quantify ribose degradation by condensation with TBA (Elizabeth \& Rao, 1990). Hydroxyl radical was generated by the $\mathrm{Fe}^{3+}$ - ascorbate - EDTA - $\mathrm{H}_{2} \mathrm{O}_{2}$ system (Fenton reaction). From the stock concentration of $2 \mathrm{mg} / \mathrm{ml}$, 5 different concentration of extracts were mixed with $500 \mu \mathrm{l}$ reaction mixture $\left\{2\right.$ deoxy 2 ribose $(2.8 \mathrm{mM}), \mathrm{FeCl}_{3}(100 \mu \mathrm{m})$, EDTA $(100 \mu \mathrm{m}), \mathrm{H}_{2} \mathrm{O}_{2}(1.0 \mathrm{mM})$, ascorbic acid $(100 \mu \mathrm{m})$ in $\mathrm{KH}_{2} \mathrm{PO}_{4}$ - $\mathrm{KOH}$ buffer (20 mM; pH 7.4) \} was made up to a final volume of $1 \mathrm{ml}$. Control was taken without a test sample but in an equivalent amount of distilled water. After incubation for one hour at $37^{\circ} \mathrm{C}$, $2.8 \%$ TCA and $1 \mathrm{ml}$ of $1 \%$ aqueous TBA were added and reacted at $90^{\circ} \mathrm{C}$ for 15 minutes for color development. The absorbance of the cooling solution was measured against a blank solution at $532 \mathrm{~nm}$. Hydroxyl radical scavenging was calculated as:

$$
\% \text { Inhibition }=\frac{(\text { Control }- \text { Test })}{\text { Control }} \times 100
$$

\subsection{Cell culture}

Mouse monocyte macrophage (Raw264.7) cells were initially procured from National Centre for Cell Sciences (NCCS), Pune, India, and maintained Dulbecco's modified Eagles medium, DMEM (Sigma Aldrich, USA). The cell lines were grown in DMEM with $10 \%$ FBS, L-glutamine, sodium bicarbonate, and the antibiotic solution containing Penicillin (100U/ml), Streptomycin 
$(100 \mathrm{~g} / \mathrm{ml})$, and Amphotericin B $(2.5 \mathrm{~g} / \mathrm{ml})$. The cultured cell lines were kept at $37^{\circ} \mathrm{C}$ in a humidified $5 \% \mathrm{CO}_{2}$ incubator (NBS Eppendorf, Germany). Two days old confluent monolayers of cells were trypsinized, suspended in a $10 \%$ growth medium, seeded in 96 wells of a tissue culture plate at $37^{\circ} \mathrm{C}$ in a humidified $5 \% \mathrm{CO}_{2}$ incubator, and then incubated for 24 hours. $1 \mathrm{mg}$ of bark extract was dissolved in 1mL DMEM using a cyclomixer (stock sample), and then the sample was filtered using a $0.22 \mu \mathrm{m}$ Millipore syringe filter to ensure sterility. After incubation, growth medium was discarded and freshly prepared stock samples in 5\% DMEM were serially diluted $(100 \mu \mathrm{g}, 50 \mu \mathrm{g}, 25 \mu \mathrm{g}, 12.5 \mu \mathrm{g}, 6.25 \mu \mathrm{g}$ in $500 \mu \mathrm{l}$ of $5 \%$ DMEM). 100 $\mu 1$ of diluted samples were added to corresponding wells (in triplicates) and incubated in a humidified $5 \% \mathrm{CO}_{2}$ incubator at $37^{\circ} \mathrm{C}$. The cell viability was examined using an inverted phase-contrast microscope (Olympus CKX41 camera equipped with an Optika Pro5 CCD), followed by MTT assays. Microplate readers were used to measure absorbance values at a wavelength of $570 \mathrm{~nm}$. The formula was used to calculate the percentage of growth inhibition,

$$
\% \text { cell viability }=\frac{\text { Mean OD Samples }}{\text { Mean OD of control }} \times 100
$$

\subsection{ELISA estimation of inflammatory mediators}

The ELISA estimation is normally performed to quantify the level of different inflammatory markers (antigens) using a specific antibody (Engvall \& Perlman, 1971). The confluent raw 246.7 cells were treated with a sample (PRME) at a stock concentration of $1 \mathrm{mg} / \mathrm{ml}$ and kept at $37^{\circ} \mathrm{C}$ for $24 \mathrm{hrs}$ in a $\mathrm{CO}_{2}$ incubator. The supernatant was collected for protein estimation and transferred $100 \mu \mathrm{L}$ to 96 well plates and incubated at $37^{\circ} \mathrm{C}$ overnight for cell lysate coating. The cell lysate coated wells were blocked using blocking buffer containing $0.2 \%$ gelatin in $0.05 \%$ Tween 20 in PBS and incubated for 1 hour at room temperature, washed twice with PBS TWEEN20 and 100 $\mu$ of Cox-2, IL1- $\beta$, IL-6, and NF-kB primary antibodies (Santa Cruz, USA) was added and left for 2 hours at room temperature, washed again with PBS TWEEN (2 times). $100 \mu \mathrm{L}$ of secondary antibody (HRP Conjugate, Santa Cruz, USA) was added and kept at room temperature for 1 hour, washed with PBS TWEEN two times, and added $200 \mu \mathrm{L}$ chromogen; Odianizdine hydrochloride, incubated at room temperature for 30 minutes. The reaction was terminated by adding $50 \mu 15 \mathrm{~N} \mathrm{HCl}$ and the absorbance was read at $450 \mathrm{~nm}$ after 5-30 minutes in an ELISA reader (Islam \& Jones, 1988).

$$
\text { Activity of Antibody }=\frac{\text { OD Value }}{\text { Protein concentration }}
$$

\subsection{Animal studies}

Healthy female Sprague Dawley rats of 2-3month age and 200$250 \mathrm{~g}$ body weight, procured from the animal house, Department of Biochemistry, University of Kerala were used for the study.
Animals were treated as per CPCSEA guidelines and the experimental protocol was approved by the Institutional animal ethical committee order number as follows; IAEC-2-KU-01/201819-BCH-AAR and IAEC-KU-09/2018-19-BCH-AAR; the dosedependent toxicity study was sanctioned to be conducted in agreement with OECD guidelines. Rats were grouped into five groups of six animals each, group: I - control rats (normal saline) and group (II, III, IV, V) were administered with different doses of PRME 50, 300, 500, 1000mg/kg/day respectively and kept under observation for 14 days. Animals were scarified on the $15^{\text {th }}$ day; blood was collected for biochemical investigations and stress marker studies. SOD activity was determined by the method described by Kakkar et al. (1984). The catalase activity was determined by the method of Maehly \& Chance (1954). Glutathione reductase was assayed by the method of David \& Richard (1983). The glutathione peroxidase was estimated by the method of Lawerence \& Burk (1976) as modified by Agergaard \& Jense (1982). The glutathione content of the tissues were determined by the procedure described by Patterson \& Lazarow (1955).

\subsection{Statistical analysis}

Graph Pad Prism 5 software (GraphPad Software Inc.,) was used to calculate the Standard deviation, Two-way analysis of variance (ANOVA), and $\mathrm{EC}_{50}$ values of different antioxidant assays. The Pearson correlation coefficient and $\mathrm{p}$ values $<0.05$ were regarded as significant. Values expressed are means of three replicate determinations \pm standard deviation.

\section{Results and discussion}

With the help of a single assay, we cannot understand the complete antioxidant profile of any natural product because the biopotentiality of plant extracts is influenced by various physicochemical factors in a symbiotic pattern and most of the natural antioxidants are multifunctional due to the presence of abundant phytochemicals. So it is very essential to study the complete antioxidant profiling, to understand the antioxidant potential and its interactive mechanisms to eliminate free radical initiated toxicity in various disease conditions and also in metabolic pathways (Gan et al., 2010).

\subsection{Antioxidant activity by ABTS and Total antioxidant assay}

The ABTS radical scavenging and total antioxidant activity of PRME and PRAQ were estimated and compared with standard (ascorbic acid). The highest scavenging activity was exhibited by PRME followed by PRAQ (Figure 1). Being simple and reliable antioxidant measurement, the total antioxidant assay has been commonly used to evaluate the antioxidant capacity of plant extracts. The method is based on the reduction of $\mathrm{Mo}^{6+}$ to $\mathrm{Mo}^{5+}$ by 
the antioxidants present in natural products and results in the formation of green phosphomolybdenum complex with the maximum absorption being calorimetrically measured at $695 \mathrm{~nm}$. The transfer of electrons from antioxidants to neutralize toxic radicals depends on the structure and binding moieties of antioxidant molecules (Lobo et al., 2010). The PRME showed a higher reduction $(61.09 \mathrm{~g} \mathrm{AA} / 100 \mathrm{~g}$ extract) followed by PRAQ (57.96g AA/100g extract). The antioxidant activity confirmed the medicinal importance of both plant extracts as naturally occurring antioxidants.

ABTS is a protonated radical having a characteristic maximum absorbance at $734 \mathrm{~nm}$ and decreases with the scavenging of the $\mathrm{ABTS}^{+}$radicals. The plant extract possessing ABTS free radical scavenging activity indicated that it can act as a hydrogen donor, which converts free radicals to more stable products and thereby terminating the oxidation process (Ilyasov et al., 2020). The high molecular weight phenolics have an excellent capacity to scavenge $\mathrm{ABTS}^{+}$free radicals. Since both the extracts PRME and PRAQ can quench free radicals, thereby lowering the lipid oxidation process via chain-breaking reaction, these molecules can be considered as novel antioxidants based on detailed biological studies. This might be due to the presence of hydroxyl groups in ortho, meta, and para positions of the phenolic compounds present in these extracts (Mathew et al., 2015). The studies on the antioxidant activity of different medicinal plants have indicated that the phenolic compounds are key players to scavenge ABTS radicals. The results showed that PRME with an $\mathrm{EC}_{50}$ value of $46.09 \mu \mathrm{g} / \mathrm{ml}$ followed by PRAQ fractions $(52.08 \mathrm{ug} / \mathrm{ml})$ showed good ABTS scavenging capacity, which can lower the oxidation process by reducing free radicals in a dose-dependent manner $(\mathrm{p}<0.05)$. The correlation analysis showed good Pearson co-efficient relation between standard AA ( $r=0.8988)$ and PRME $(r=0.8585)$ and PRAQ with $r$ value 0.9160 respective.

\subsection{Antioxidant activity by Nitric oxide and Superoxide radical} scavenging assay

The nitric oxide and superoxide radical scavenging ability of both methanolic and aqueous bark extracts were compared with the ascorbic acid standard. The PRME showed better radical scavenging activity than PRAQ and is shown in figure 2. Nitric
Total antioxidant assay

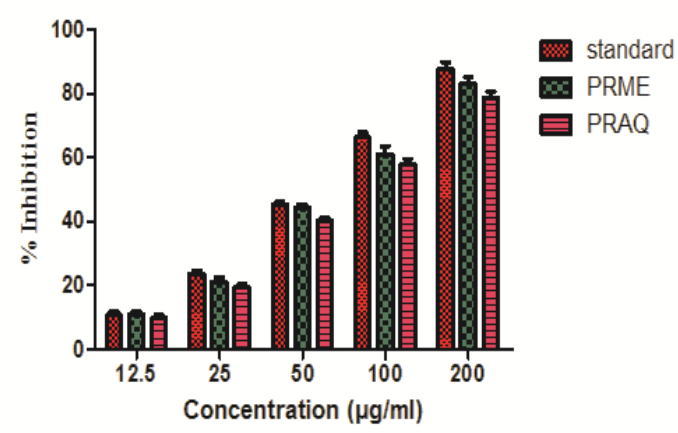

ABTS Assay

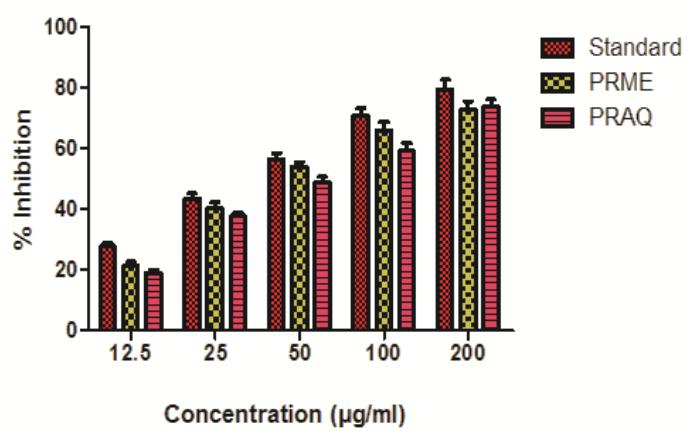

Figure 1 The PRME extract gave the highest TAA with $\mathrm{EC}_{50}$ value $81.85 \mu \mathrm{g} / \mathrm{ml}$ followed by aqueous $\mathrm{EC}_{50}$ value $86.26 \mu \mathrm{g} / \mathrm{ml}$. $(\mathrm{p}<0.05)$. Values are expressed as mean \pm standard deviation $(\mathrm{n}=3)$.

Nitric oxide scavenging assay

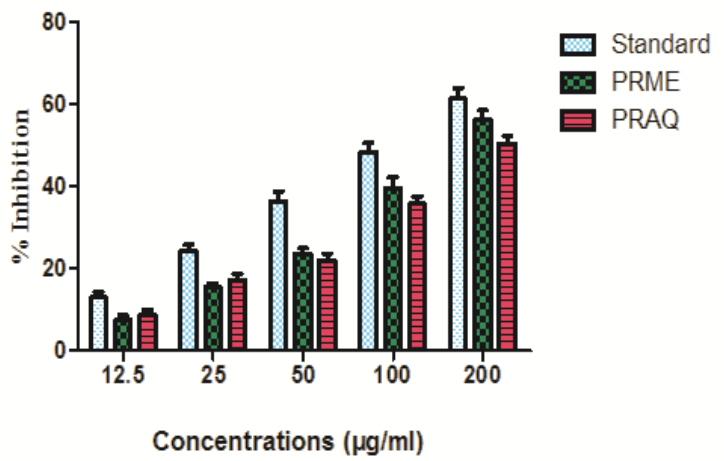

Superoxide scavenging assay

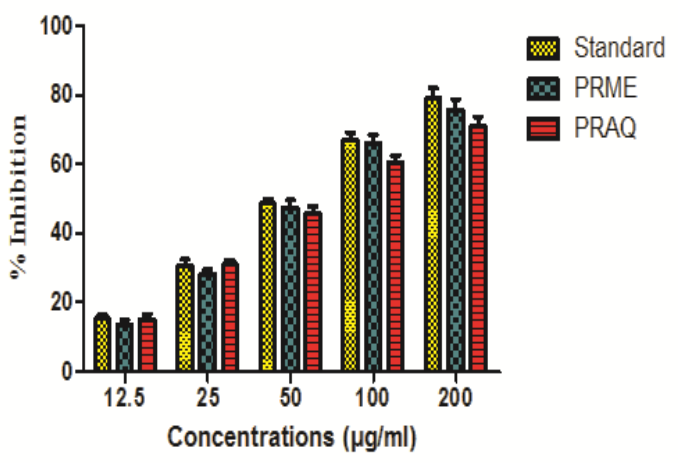

Figure 2 Shows the Nitric oxide and Superoxide radical scavenging activity of PRME and PRAQ ( $<<0.05)$. Values are expressed as mean \pm standard deviation $(n=3)$. 
oxide is an important chemical mediator involved in inflammatory mechanisms. Reactive nitrogen species (RNS) are free radicals that are formed due to the interaction of NO with oxygen, which leads to the production of different intermediates such as stable nitrates, $\mathrm{NO}_{2}, \mathrm{~N}_{2} \mathrm{O}_{4}$, and $\mathrm{N}_{3} \mathrm{O}_{4}$ (Ozcan \& Ogun, 2015). The singlet oxygen $\left(\mathrm{O}_{2}\right)$ and $\mathrm{NO}$ radicals are directly involved in the lipid peroxidation process and chronic inflammatory cascades (Valko et al., 2007). The results showed a dose-response increase in the capacity to quench hydroxyl radicals for all the concentrations studied (Figure 2). A concentration-dependent scavenging of NO radicals by the PRME was significant at $\mathrm{p}<0.05(\mathrm{r}=0.9786, \mathrm{p}=0.01)$, followed by PRAQ ( $r=0.9778$ ) on correlation analysis. The PRME fraction showed the highest $\mathrm{OH}$ scavenging potential $\left(\mathrm{EC}_{50}\right.$ value of $177.21 \mu \mathrm{g} / \mathrm{ml}$ ) in a concentration-dependent manner followed by PRAQ fraction $197.82 \mu \mathrm{g} / \mathrm{ml}$.

The superoxide scavenging ability as measured by the riboflavinNBT-light system indicates that the anion radicals produced due to the photochemical reduction of riboflavin lead to a decrease in blue formazan solution absorbance at $560 \mathrm{~nm}$. The $\mathrm{O}_{2}$ anion radical was inhibited in a dose-dependent manner as shown in figure 2. The $\mathrm{EC}_{50}$ values of PRME and PRAQ were $76.24 \mu \mathrm{g} / \mathrm{ml} \& 82.98 \mu \mathrm{g} / \mathrm{ml}$ respectively. These results indicated that $\mathrm{PR}$ bark fractions, especially methanolic fractions showed significant inhibition of superoxide radical, compared to positive control ascorbic acid (EC ( $_{50}$ values $75.18 \mu \mathrm{g} / \mathrm{ml}$ ).

\subsection{Hydroxyl radical scavenging assay}

The hydroxyl radical scavenging capacity of both PRME and PRAQ, compared with standard gallic acid, is summarised in table 1. Hydroxyl radical is one of the dangerous reactive oxygen species in a biological system having the capacity to damage most of the biomolecules in our body. There is no specific enzyme or molecules available in the human body to eliminate or minimize their harmful effects (He et al., 2017). This free radical can combine with unwanted DNA nucleotides, resulting in a mismatch of base sequences and leading to ageing, genetic damages, and carcinogenesis (Sharifi-Rad et al., 2020). Hence eliminating the hydroxyl radical is a very crucial defence mechanism to keep our body healthy and the ability of PRME to reduce hydroxyl radical is considered to be good for preventing the lipid peroxidation process. The results showed a dose-response increase in the capacity to quench hydroxyl radicals for all the concentrations studied (Table 1). Inhibition of hydroxyl radicals by the methanol extract was found to be significant at $\mathrm{p}<0.05(\mathrm{r}=0.9009, \mathrm{p}=0.01)$ with gallic acid standard ( $\mathrm{r}=0.9161)$, followed by aqueous $(\mathrm{r}=0.8615)$ on correlation analysis. The PRME fraction showed the highest $\mathrm{OH}$ scavenging potential $\left(\mathrm{EC}_{50}\right.$ value of $\left.95.11 \mu \mathrm{g} / \mathrm{ml}\right)$ in a concentration-dependent manner followed by PRAQ fraction $181.29 \mu \mathrm{g} / \mathrm{ml}$.

\subsection{Antioxidant assays by correlation analysis}

The results of the different antioxidant assays were compared, correlated with each other, and summarized in table 2. Significant correlations ( $p$-value $<0.001)$ were observed for all the antioxidant assays. The TAA assay values showed good correlation coefficient ' $r$ ' values for ascorbic acid standard, PRME, and PRAQ with $0.9509,0.9522$, and 0.9560 respectively, Superoxide radical assay with ascorbic acid ( $\mathrm{r}=0.9150)$, PRME ( $\mathrm{r}=0.9107)$, and PRAQ $(\mathrm{r}=0.9032)$. In hydroxyl radical scavenging assay also standard $(\mathrm{r}=0.9161)$ showed close value to PRME ( $\mathrm{r}=0.9009)$. The correlation values fall in a range of $(r=0.8585)$ to $(r=0.9786)$, and this is due to the antioxidant activity of plants extracts which are influenced by various compounds like alkaloids, flavonoids, phenolics \& glycosides (Tungmunnithum et al., 2018).

Table 1 Hydroxyl radical scavenging activity of PRME and PRAQ

\begin{tabular}{cccc|}
$\begin{array}{c}\text { Concentrations } \\
(\mu \mathrm{g} / \mathrm{ml})\end{array}$ & Gallic acid & PRME & PRAQ \\
\hline 25 & $16.50 \pm 1.43$ & $17.16 \pm 1.06$ & $13.50 \pm 1.46$ \\
\hline 50 & $31.36 \pm 1.53$ & $34.05 \pm 1.34$ & $33.24 \pm 1.57$ \\
\hline 100 & $40.70 \pm 1.67$ & $43.59 \pm 173$ & $38.62 \pm 1.43$ \\
\hline 200 & $56.58 \pm 2.46$ & $52.73 \pm 1.95$ & $45.81 \pm 1.81$ \\
\hline 400 & $65.66 \pm 2.35$ & $63.11 \pm 2.47$ & $55.16 \pm 2.85$ \\
\hline
\end{tabular}

Values are expressed as mean \pm standard deviation $(n=3)$.

Table 2 Comparative correlation analysis of different antioxidant assays

\begin{tabular}{|cccc|}
\hline \multirow{2}{*}{ Antioxidant assays } & \multicolumn{3}{c|}{ Pearson co-efficient values (r) } \\
& Standard & PRAQ & PRME \\
\hline Total antioxidants assay & 0.9509 & 0.9560 & 0.9522 \\
\hline Superoxide radical assay & 0.9150 & 0.9032 & 0.9107 \\
\hline Nitric oxide radical assay & 0.9427 & 0.9786 & 0.9778 \\
\hline Hydroxyl radical assay & 0.9161 & 0.9009 & 0.8615 \\
\hline ABTS radical assay & 0.8988 & 0.9160 & 0.8585 \\
\hline
\end{tabular}

Values are expressed as mean \pm standard deviation $(\mathrm{n}=3)$.

\subsection{MTT assay}

The MTT assay is used to evaluate the cellular toxicity of any drug or plant material in In vitro culture. During plant material characterization, preliminary quantifying the toxicity in cell lines is a crucial step before moving to higher level molecular studies. The MTT assay showed good cellular viability of PRME up to a concentration of $100 \mu \mathrm{g} / \mathrm{ml}$ (Figure 3). The anti-inflammatory effect of PRME on the LPS-induced inflammation in RAW 264.7 cells (murine macrophage cell line) was assessed using MTT assay and the entire plate was observed after 24 hours of treatment in an inverted phase contrast tissue culture microscope. The morphological changes in cells including shrinkage, rounding, 
granulation, and cytoplasmic vacuolization were regarded as the symptoms of cytotoxicity. The results showed that PRME does not influence the viability of RAW 264.7 cells and the cellular competency was selected for detailed study. LC50 Value of PRME was found to be $106.869 \mu \mathrm{g} / \mathrm{ml}$ and the LC50 concentration was selected for evaluating the inflammatory mediators (Figure 3 ).

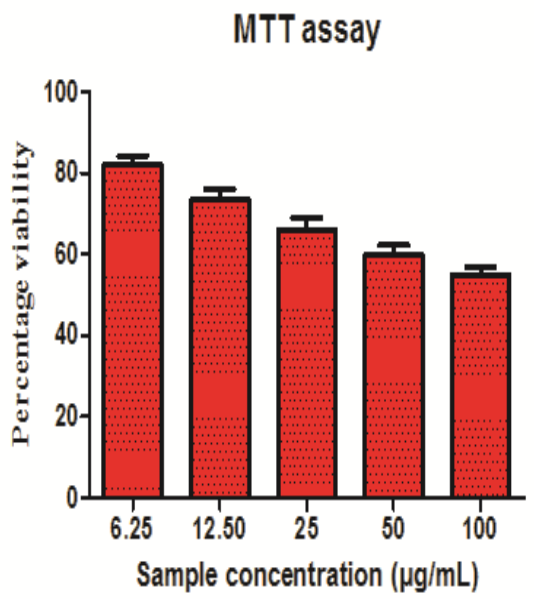

Figure 3 Effect of PRME on RAW cells. The graph represents the percentage cell viability on treatment with different concentrations of the extract. The values are represented as mean \pm standard of three experiments.

\subsection{Inflammatory marker study}

The anti-inflammatory activity of PRME was evaluated using the ELISA method. On LPS treatment, the RAW cells shows the increased activity of inflammatory mediators, after the addition of PRME significantly reduced the activity of cyclooxygenase-2, interleukins - $1 \beta$ and 6 , and nuclear factor-kB (Table 3). The LPS treated wells showed the antibody activity of Cox-2, IL-1 $\beta$, IL-6, and NF-kB in the order respectively 1.34996, 1.569258, 1.520547, and 1.624434, and this activity is significantly reduced after PRME treatment and incubation period for $24 \mathrm{hrs}$ as 1.15089 , 1.084416 , 1.03618 and 1.102227 (Table 3). During LPS treatment, the macrophages get activated and various inflammatory mediators and cytokines (Cox-2, IL-1 $\beta$, IL-6) are synthesized, which enhance the microenvironment for inflammation and further aggravate the conditions. The interleukins IL-1 $\beta$, IL- 6 plays an important role in enhancing autoimmune diseases, bacterial infections, metabolic syndromes, malignant disorders, acute and chronic inflammation (Kany et al., 2019). These mediators along with other subsidiary factors activate the transcription factor NF-kB, a crucial checkpoint of inflammatory pathways because NF-kB controls nearly 150 genes involved in inflammation pathways, immune defense as well as in cell proliferation and differentiation mechanisms (Panday et al., 2016). During the LPS activation, NF$\mathrm{kB}$ translocates from the cytoplasm to the nuclear region and acts as a transcription factor for the synthesis of inflammatory enzymes and cytokines. Any agents which can inhibit or reduce the level of inflammatory mediators are considered good anti-inflammatory agents. The result demonstrated that PRME can inhibit the activity of inflammatory enzyme Cox-2 along with the interleukins, thereby reducing the production of pro-inflammatory cytokines, including IL-6 and IL-1 $\beta$ in RAW 264.7 cells stimulated by LPS; which directly or indirectly suppress the activation of transcription factor NF-kB. These results suggest that PRME significantly improves LPS induced inflammatory conditions in RAW cells by inhibiting the overproduction of inflammatory mediators.

\begin{tabular}{|ccc|}
\multicolumn{3}{|c|}{ Table 3 Inflammatory marker study } \\
\hline \multirow{2}{*}{ Inflammatory markers } & \multicolumn{2}{c|}{ Activity Units/mg protein } \\
& Control & Sample \\
\hline Cox-2 & 1.34996 & 1.15089 \\
\hline IL-1 $\beta$ & 1.569258 & 1.084416 \\
\hline IL-6 & 1.520547 & 1.03618 \\
\hline $\mathrm{Nf}-\mathrm{Kb}$ & 1.624434 & 1.102227 \\
\hline
\end{tabular}

Values are expressed as mean \pm standard deviation $(\mathrm{n}=3)$.

The antioxidant enzymes and stress markers are investigated from the liver tissue obtained from animal acute toxicity study for 14 days. After the PRME treatment, the animals were scarified and quantified the levels of different stress mediators in liver tissue are summarised in table 4 . The first line antioxidant enzyme defense mechanism is from superoxide dismutase (SOD), catalase, and glutathione peroxidize, which convert the toxic superoxide and hydrogen peroxide radicals into water (Ighodaro \& Akinloye, 2018). The PRME treated animals up to a concentration of $1000 \mu \mathrm{g} / \mathrm{ml}$ did not show any significant variation in antioxidant enzymes when compared to normal rats. The enzyme catalase and SOD of the treated group showed good linearity with control rats, the glutathione peroxidize values exhibited a constant increase in the antioxidant activity in PRME treated animals in the range, $(35.71 \pm 1.05$ to $39.73 \pm 1.72)$ from table 4 , which indicated the potent antioxidant activity of PRME, and it may be due to the presence of high phenolic content in bark extracts. Manna et al. (2009) reported that the bark extract of $P$. acerifolium significantly reduced alcohol-induced ulceration on oxidative damages in adult Charles foster rats, pre-treatment elevated the enzymes SOD, CAT, and GSH content when compared to the control group animal.

The oxidoreductase enzyme, glutathione reductase (GR) enhances the reduction of oxidized glutathione to reduced glutathione (GSH) in the presence of NADPH as a co-factor. The antioxidant enzyme (GR) and cellular thiol antioxidant (GSH) play a major role in cellular defense against drug and toxin-induced hepatotoxicity, associated with oxidative stress (Espinosa-Diez et al., 2015). Being a sensitive indicator of toxicity, both the values of GSH and GR in PRME treated groups were compared with normal control rats, the 
Table 4 Stress marker study in liver tissue of rats

\begin{tabular}{|cccccc|}
\hline Parameters & Group I & Group II & Group III & Group IV & Group V \\
\hline GPx(U/mg protein) & $32.56 \pm 1.38$ & $32.69 \pm 1.34$ & $34.88 \pm 1.34$ & $34.80 \pm 2.02$ & $33.85 \pm 1.79$ \\
\hline GSH (U/mg protein) & $82.86 \pm 1.86$ & $82.93 \pm 2.07$ & $82.65 \pm 1.91$ & $84.033 \pm 1.95$ & $83.78 \pm 2.06$ \\
\hline $\begin{array}{c}\text { GRd( } \mu \text { mole of glutathione reduced/ } \\
\text { min/mg protein) }\end{array}$ & $144.67 \pm 4.23$ & $143.61 \pm 3.31$ & $146.62 \pm 4.84$ & $145.06 \pm 4.49$ & $143.22 \pm 4.12$ \\
\hline SOD (U/mg protein) & $2.41 \pm 0.19$ & $2.45 \pm 0.123$ & $2.48 \pm 0.12$ & $2.57 \pm 0.18$ & $2.51 \pm 0.26$ \\
\hline $\begin{array}{c}\text { Catalase }\left(\mu \text { mol of } \mathrm{H}_{2} \mathrm{O}_{2} \text { consumed/ }\right. \\
\text { min/mg protein) }\end{array}$ & $7.43 \pm 0.38$ & $7.57 \pm 0.25$ & $7.53 \pm 0.21$ & $7.59 \pm 0.28$ & $7.56 \pm 0.237$ \\
\hline
\end{tabular}

Values are expressed as mean \pm standard deviation $(n=6)$.

PRME treated group showed a slight increase in the values of $\mathrm{GSH}$, a strong non-enzymatic antioxidant in 500 and $1000 \mu \mathrm{g} / \mathrm{ml}$ treated groups, at the same time the levels of GR are comparatively high in all treated groups when compared to control rats $147.65 \pm$ 4.08 (Table 4). From this study, we concluded that the PRME is rich in antioxidants, compared to PRAQ, and showed excellent antioxidant activity under In vitro condition; stress marker studies in rat liver cells confirmed the non-toxicity of PRME up to a concentration of $1000 \mu \mathrm{g} / \mathrm{ml}$ for 14 days of treatment. MTT assay and inflammatory marker studies revealed the anti-inflammatory activity of PRME in reducing the LPS induced inflammation in RAW246.7 cells.

\section{Conclusion}

The present study revealed that PRME possesses excellent antioxidant and anti-inflammatory properties and could serve as free radical inhibitors, scavengers, or primary antioxidants. A positive correlation was detected for phenolic content and free radical scavenging activity of PRME. Toxicity evaluation studies on female Spargue Dawley rats showed that PRME up to a concentration of $1000 \mu \mathrm{g} / \mathrm{ml}$ for 14 days is not harmful, indicating the prospects for more advanced investigations to better understand PRME's mechanism as a pharmacological agent.

\section{Author Contributions}

The authors contributed to this work as follows; extraction, antioxidant assays, anti-inflammatory analyses, and animal experiments were performed by $\mathrm{R} \mathrm{J}$ Anish under the supervision of Arun R Rauf. Both the authors contributed to statistical and data analysis, manuscript preparation, reviewed the article, edited, and approved the manuscript.

\section{Conflicts of Interest}

The authors declare no conflict of interest.

\section{Acknowledgment}

We would like to thank, Department of Biochemistry, University of Kerala, Trivandrum, Kerala, India for providing an infrastructural facility to perform our experiments.

\section{Research funding}

This work was financially supported by a research fund (20192020), University of Kerala, Trivandrum.

\section{Abbreviations}

PRME: P. rubiginosum methanolic extract; PRAQ: P. rubiginosum aqueous extract; ROS: reactive oxygen species; ABTS:2, 2'azinobis 3 ethyl benzothiazoline 6- sulfonic acid; TAA: total antioxidant activity; (MTT) : 3-(4,5-dimethylthiazol-2-yl)-2,5diphenyl tetrazolium bromide; cox-2: cyclooxygenase-2; IL-1 $\beta$ : interleukins-1 $\beta$; IL-6: interleukins-6; NF-kB: nuclear factor kappa-light-chain-enhancer of activated B cells; GR: glutathione reductase; GPx: glutathione peroxidise; GSH: reduced glutathione.

\section{References}

Agergaard N, Jense PT (1982) Procedure for blood glutathione peroxidise determination in cattle and swine. Acta Veterinaria Scandinavica 23:515-27.

Anish RJ, Sajeetha S, Rauf AA (2021) Cytotoxic evaluation and phytochemical screening of an ethnomedicinal plant: Pterospermum rubiginosum from southern Western Ghats. Journal of Medicinal Plants Studies 9(5): 51-58.

Azmin SNHM, Nor MSM (2020) Chemical fingerprint of Centella asiatica's bioactive compounds in the ethanolic and aqueous extracts. Advances in Biomarker Sciences and Technology 2: 35-44.

Babich O, Sukhikh S, Prosekov, A, Asyakina L, Ivanova S (2020) Medicinal Plants to Strengthen Immunity during a Pandemic. Pharmaceuticals 13(10):313. 
David M, Richard JS (1983) Methods of enzymatic analysis 3. In Bermeyyer J, Mariare GB (Eds.), Veriag Chemic Weinheina Dec, Field Beach Florida based, Pp. 358.

Elizabeth K, Rao MWA (1990) Oxygen radical scavenging activity of Curcumin. International Journal of Pharmaceutics 58:237-240.

Engvall E, Perlman P (1971) Enzyme-linked immunosorbent assay (ELISA). Quantitative assay of immunoglobulin G. Immunochemistry $\quad 8(9)$ : $\quad 871-874$. doi: $10.1016 / 0019$ 2791(71)90454-x.

Espinosa-Diez C, Miguel V, Mennerich D, Kietzmann T, Sánchez-Pérez P, Cadenas S, Lamas S (2015) Antioxidant responses and cellular adjustments to oxidative stress. Redox Biology 6: 183-197.

Gan RY, Xu XR, Song FL, Kuang L, Li HB (2010) Antioxidant activity and total phenolic content of medicinal plants associated with prevention and treatment of cardiovascular and cerebrovascular diseases. Journal of Medicinal Plants Research 4: 2438-2444.

Hasanuzzaman M, Bhuyan MHM, Zulfiqar F, Raza A, Mohsin SM, Mahmud JA, Fujita M, Fotopoulos V (2020) Reactive oxygen species and antioxidant defense in plants under abiotic stress: Revisiting the crucial role of a universal defense regulator. Antioxidants 9(8): 681.

He L, He T, Farrar S, Ji L, Liu T, Ma X (2017) Antioxidants maintain cellular redox homeostasis by elimination of reactive oxygen species. Cellular Physiology and Biochemistry 44(2): 532553.

Ighodaro OM, Akinloye OA (2018) First line defence antioxidantssuperoxide dismutase (SOD), catalase (CAT) and glutathione peroxidase (GPX): Their fundamental role in the entire antioxidant defence grid. Alexandria Journal of Medicine 54(4): 287-293.

Ilyasov IR, Beloborodov VL, Selivanova IA, Terekhov RP (2020) ABTS/PP decolorization assay of antioxidant capacity reaction pathways. International Journal of Molecular Sciences 21(3): 1131.

Islam MR, Jones RC (1988) An enzyme-linked immunosorbent assay for measuring antibody titre against avian reovirus using a single dilution of serum. Avian Pathology 17(2): 411-425.

Kakkar P, Das B, Viswanathan PN (1984) A modified spectrophotometric assay of superoxide dismutase. Indian Journal of Biochemistry and Biophysics 21: 130-132.

Kany S, Vollrath JT, Relja B (2019) Cytokines in Inflammatory Disease. International Journal of Molecular Sciences 20(23): 6008.
Kornienko JS, Smirnova IS. Pugovkina NA, Ivanova JS, Shilina MA, Grinchuk TM, Shatrova AN, Aksenov ND, Zenin VV, Nikolsky NN, Lyublinskaya OG (2019) High doses of synthetic antioxidants induce premature senescence in cultivated mesenchymal stem cells. Scientific Reports 9(1): 1-13.

Kurutas EB (2015) The importance of antioxidants which play the role in cellular response against oxidative/nitrosative stress: current state. Nutrition Journal 15(1): 1-22.

Lawrence RA, Burk RF (1976) Glutathione peroxidase activity in selenium-deficient rat liver. Biochemical and Biophysical Research Communications 71: 952-8.

Lobo V, Patil A, Phatak A, Chandra N (2010) Free radicals, antioxidants and functional foods: Impact on human health. Pharmacognosy Reviews 4(8): 118.

Lourenço SC, Moldão-Martins M, AlvesVD (2019) Antioxidants of Natural Plant Origins: From Sources to Food Industry Applications. Molecules 24(22): 4132.

Maehly AC, Chance B (1954) The assay of catalases and peroxidases. Methods of Biochemical Analysis 1: 357-424.

Manna AK, Jena JI, Behera AK, Roy DI, Manna SU, Karmakar S, Kar S (2009) Effect of Pterospermum acerifolium bark extract on oxidative damages in the gastric tissue during alcohol induced ulceration. International Journal of Pharmacy and Pharmaceutical Sciences 1(1): 51-9.

Mathew S, Abraham TE, Zakaria ZA (2015) Reactivity of phenolic compounds towards free radicals under In vitro conditions. Journal of Food Science and Technology 52(9): 5790-5798.

Ozcan A, Ogun M (2015) Biochemistry of reactive oxygen and nitrogen species. Basic principles and clinical significance of oxidative stress, Pp. 37-58. Available at https://www.intechopen.com/chapters/48975.

Panday A, Inda ME, Bagam P, Sahoo MK, Osorio D, Batra S (2016) Transcription factor NF-אB: an update on intervention strategies. Archivum Immunologiae et Therapiae Experimentalis 64(6): 463-483.

Patel A, Patel A, Patel A, Patel NM (2010) Determination of polyphenols and free radical scavenging activity of Tephrosia purpurea linn leaves (Leguminosae). Pharmacognosy Research 2(3): 152-158.

Patterson JW, Lazarow A (1955) Determination of glutathione. Methods Biochemical Analysis 2: 259-278. 
Pizzino G, Irrera N, Cucinotta M, Pallio G, Mannino F, Arcoraci V, Squadrito F, Altavilla D, Bitto A (2017) Oxidative stress: harms and benefits for human health. Oxidative Medicine and Cellular Longevity 8416763. doi:10.1155/2017/8416763.

Re R, Pellegrini N, Proteggente A, Pannala A, Yang M, RiceEvans C (1999) Antioxidant activity applying an improved ABTS radical cation decolorization assay. Free Radical Biology and Medicine 26: 1231-1237.

Sharifi-Rad M, Anil Kumar NV, Zucca P, Varoni EM, Dini L, Panzarini E, Rajkovic J, Tsouh Fokou PV, Azzini E, Peluso I, Mishra PA, et al. (2020) Lifestyle, oxidative stress, and antioxidants: Back and forth in the pathophysiology of chronic diseases. Frontiers in Physiology 11: 694. doi: 10.3389/fphys.2020.00694. eCollection 2020.

Shields HJ, Traa A, Raamsdonk VJM (2021) Beneficial and Detrimental Effects of Reactive Oxygen Species on Lifespan: A Comprehensive Review of Comparative and Experimental Studies. Frontiers in Cell and Developmental Biology 9: 181. doi: 10.3389/fcell.2021.628157.

Srivastava S, Singh D, Patel S, Singh MR (2017) Role of enzymatic free radical scavengers in management of oxidative stress in autoimmune disorders. International Journal of Biological Macromolecules 101: 502-517.

Subhasree BR, Baskar R, Keerthana L (2009) Evaluation of antioxidant potential in selected green leafy vegetables. Food Chemistry 115: 1213-1220.
Subhose V, Srinivas P, Narayana A (2005) Basic principles of pharmaceutical science in Ayurvěda. Bulletin of the Indian Institute of History of Medicine (Hyderabad) 35(2): 83-92.

Tungmunnithum D, Thongboonyou A, Pholboon A, Yangsabai A (2018) Flavonoids and other phenolic compounds from medicinal plants for pharmaceutical and medical aspects: An overview. Medicines 5(3): 93.

Valento P, Fernandes E, Carvalho F, Andrade PB, Seabra RM, Bastos ML (2002) Antioxidant activity of Hypericum and rosaemum Infusion: Scavenging Activity against Superoxide Radical, Hydroxyl Radical and Hypochlorous. Biological and Pharmaceutical Bulletin 25: 1320-1323.

Valko M, Leibfritz D, Moncol J, Cronin TD, Mazur M, Telser M (2007) Free radicals and antioxidants in normal physiological functions and human disease - Review. The International Journal of Biochemistry \& Cell Biology 39(1): 44-84.

Vijayan A, Liju VB, John JVR, Parthipan B, Renuka C (2007) Traditional remedies of Kani tribes of Kottoor reserve forest, Agasthyavanam, Thiruvananthapuram, Kerala. Indian Journal of Traditional Knowledge 6(4): 589-594.

Xu X, Liu A, Hu S, Ares I, Martínez-Larrañaga MR, Wang X, Martínez M, Anadón A, Martínez MA (2021) Synthetic phenolic antioxidants: Metabolism, hazards and mechanism of action. Food Chemistry 129488. DOI: https://doi.org/10.1016/ j.foodchem.2021.129488. 